\title{
COLLOSION AND ABSORPTION BEHAVIORS OF INCLUSIONS ON REFRACTORY
}

\begin{abstract}
The paper is dedicated to analysis the inclusion behavior in steel using theoretical calculation and simulation of water. The aim is to establish collision and absorption model of inclusions on refractory. The article discusses the variation of critical stay speed and critical shear with the radius of inclusions in the process of colliding, rebounding and absorbing. The results show the critical stay speed and critical shear of alumina respectively surpasses $1 \mathrm{~cm} \cdot \mathrm{s}^{-1}$ and $1 \mathrm{~N} \cdot \mathrm{m}^{-2}$, while titanium dioxide separately exceeds $4 \mathrm{~cm} \cdot \mathrm{s}^{-1}$ and $10 \mathrm{~N} \cdot \mathrm{m}^{-2}$ for the inclusions that radius is less than $2.5 \mu \mathrm{m}$. If the inclusions occur rebound after colliding, the inclusions that radius is less than $7 \mu \mathrm{m}$ will still be absorbed by the surface, while the inclusions that radius is more than $10 \mu \mathrm{m}$ can easily reenter the steel. The model coincides with the water simulation results and it is of good adaptability.

Keywords: inclusion, refractory wall surface, collision and absorption, critical stay speed
\end{abstract}

\section{Introduction}

With the improvement of continuous casting process and the development of refractory, the service life of refractory has greatly increased, but the issue that high melting-point compounds are absorbed on the wall during casting still exists, esp. when the aluminum killed steel is cast [1-2].

Inclusion in liquid steel move along the liquid and reach a certain speed when contacting with the wall surface, resulting in the absorption phenomenon. There are three movement modes when inclusions deposit and are absorbed on the wall [3-4]: inertial diffusion, random diffusion and directed migration. In the process, the inclusion speed is ignored. The comparison between thickness of laminar bottom layer and inclusion radius is regarded as the absorption judgment standard when numerically simulating the inclusion absorption, and considered that the inclusion will be absorbed by the wall surface, when its radius is less than the thickness of laminar bottom layer [5-6]. Obviously, in the above-mentioned study simulating the contact between inclusion and wall surface, the speed at which the inclusion contacts with the wall surface instantaneously was ignored, and the influence of inclusion movement speed on absorption wasn't considered.

The Author studied the process that the inclusion at the water opening reacts with the wall surface, and established an inclusion-wall surface collision and absorption model from the microscopic perspective to analyze the conditions in which the inclusion particle stays and it is absorbed on the wall surface.

\section{Study on wall collision model of inclusion particle}

The Author adopted the straight tube immersed water opening on the background of billet casting; the water opening has an inner diameter and a length of $37 \mathrm{~mm}$ and $1024 \mathrm{~mm}$ respectively, and the following assumptions are made by taking $\mathrm{Al}_{2} \mathrm{O}_{3}$ and $\mathrm{TiO}_{2}$ as inclusion examples:

(1) The wall surface is infinitely large, for the inclusion;

(2) There is a boundary layer at the wall surface. It has a thickness, a kinematic viscosity and a density of $0.99 \mathrm{~V}$, $\eta=1.0 \times 10^{-6} \mathrm{~m}^{2} \cdot \mathrm{s}^{-1}$ and $\rho_{f}=7000 \mathrm{~kg} \cdot \mathrm{m}^{-3}$ respectively, if the main flowing speed of steel liquid is $\mathrm{V}\left(100 \mathrm{~cm} \cdot \mathrm{s}^{-1}\right)$;

(3) The laminar bottom layer is about $20 \mu \mathrm{m}$ thick when the tundish level is $1000 \mathrm{~mm}$; the inclusion in steel liquid of tundish is in spherical shape, has a dimension generally smaller than $100 \mu \mathrm{m}$, and has an average density of $\rho_{i}=3500 \mathrm{~kg} \cdot \mathrm{m}^{-3}$.

\subsection{Analysis on the inclusion particle collision and absorption conditions}

The collision process is divided into two theories "hard ball model" and "soft ball model" [4], compression set occurs in the process when the inclusion acts on the wall surface, which accords with the "soft ball model", and thus the process can be divided into 3 stages, inclusion entrance, collision and it is thrown. The system of rectangular coordinates is established while the 
inclusion center with a radius of $r \mu \mathrm{m}$ is taken as the original point. See Figs. 1-2 for the collision and rebound diagrams:

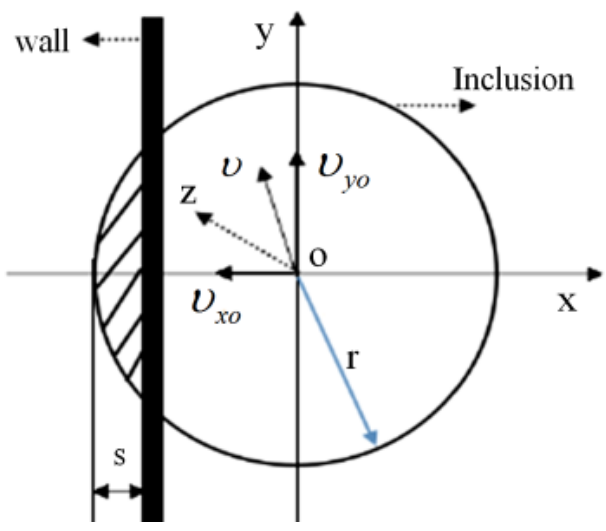

Fig. 1. Inclusion Collision

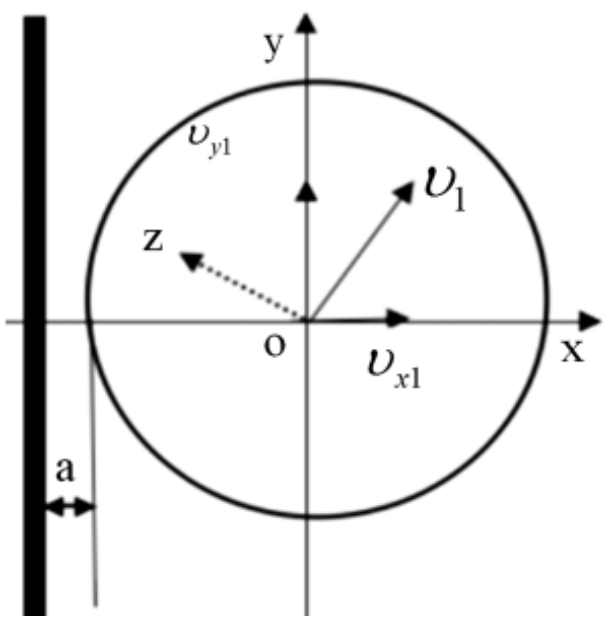

Fig. 2. Inclusion Rebound

where:

$v$ - the entering speed of inclusion, $\mathrm{cm} \cdot \mathrm{s}^{-1}$,

$v_{y 0}$ - the component velocity in the vertical direction of $v$, $\mathrm{cm} \cdot \mathrm{s}^{-1}$,

$v_{x 0}$ - the component speed of XOZ plane $\mathrm{cm} \cdot \mathrm{s}^{-1}$,

$S$ - compression set displacement, $\mathrm{m}$.

Entrance: the inclusion moves with steel liquid, and it is thrown onto the wall surface of water opening at a certain speed. The inclusion always bears the lateral resistance and shear force of steel liquid, due to the existence of boundary layer of wall surface. Yet the speed decays rapidly after the wall surface is contacted while and the displacement is small, and thus the lateral resistance is ignored.

$$
\left.\begin{array}{rl}
F_{S} & =16.03 r^{2} C_{D} V^{2} \rho_{f} \\
\tau & =C_{D} V^{2} \rho f / 2 \\
\operatorname{Re} & =V D_{p} / \eta
\end{array}\right\}
$$

where:

$F_{S}$ - shear force of steel liquid, $\mathrm{N}$,

$C_{D}$ - resistance coefficient of steel liquid, $\tau$ - shear strength of steel liquid on water opening wall surface,

$D_{p}$ - pipe diameter, $\mathrm{m}$.

Collision: The inclusion contacts with the water opening wall surface and is squeezed, till the horizontal entering velocity is zero, and deformation gradually restores under the action of wall surface rebound force. In the process, the inclusion is subject to Van der Waals' force, rebound force $F_{c}$ and wall surface friction force $F_{f}$ on wall surface, and the rebound force is provided by the classic Herz theory.

$$
\begin{aligned}
& F_{v}=A r / 6 a^{2} \\
& F_{c}=2 r^{0.5} S^{1.5} / 3 k \pi \\
& F_{f}=\left(4.12 \tau / N^{0.33}\right)\left(\left(r-r v^{2}\right) / E\right)^{0.67} N
\end{aligned}
$$

where:

$A$ - Hamaker constant,

$a$ - Van der Waals' force action distance, $\mathrm{nm}$,

$n$ - collision coefficient,

$k$ - elastic deformation coefficient,

$N$ - wall surface bearing capacity, $\mathrm{N}$,

$v$ - inclusion poisson's ratio,

$E$ - inclusion elasticity modulus.

Rebound: the inclusion is subject to absorption and rebound forces of wall surface. Steel liquid reenters, if the inclusion overcomes the absorption force and rebounds; or otherwise it will stay on the water opening wall surface, and may be absorbed by the wall surface. Energy loss occurs in collision and the bouncing speed upon collision contact is zero, if the inclusion collides with the wall surface at the initial horizontal speed $v_{x 0}$. This entering speed is called critical stay speed.

After bouncing, the inclusion bears the Van der Waals' force within 0.2 to $4 \mathrm{~nm}$ of axis $\mathrm{X}$, and the average action distance is about $2 \mathrm{~nm}$. Within a tiny distance, the speed in the direction of axis $\mathrm{Y}$ doesn't lose, and according to the energy conservation:

$$
\begin{aligned}
& W=F_{v}\left(a_{\max }-a_{\min }\right) \\
& v_{x 1}=\left[\left(e v_{x 0}\right)^{2}-(2 W / m)\right]^{0.5}
\end{aligned}
$$

where:

$W$ - Van der Waals' force work, J,

$e-$ rebound coefficient, ratio of exiting and entering speeds,

$v_{x 0}-$ initial entering speed, $\mathrm{cm} \cdot \mathrm{s}^{-1}$,

$v_{x 1}-$ critical stay speed, $\mathrm{cm} \cdot \mathrm{s}^{-1}$,

$m$ - inclusion mass, $\mathrm{kg}$.

According to Eq. (3), if $v_{x 1}=0$, the inclusion closely attaches onto the wall surface and can impossibly glide or roll under the action of vertical speed; if $v_{x 1}>0$, the inclusion rebounds and reenters the steel liquid.

If the rebound coefficient $e \in(0 \sim 1)$ [7-8], the critical stay speeds of $\mathrm{Al}_{2} \mathrm{O}_{3}$ and $\mathrm{TiO}_{2}$ inclusions are obtained based on Eq. (3), as shown in Fig. 3. 


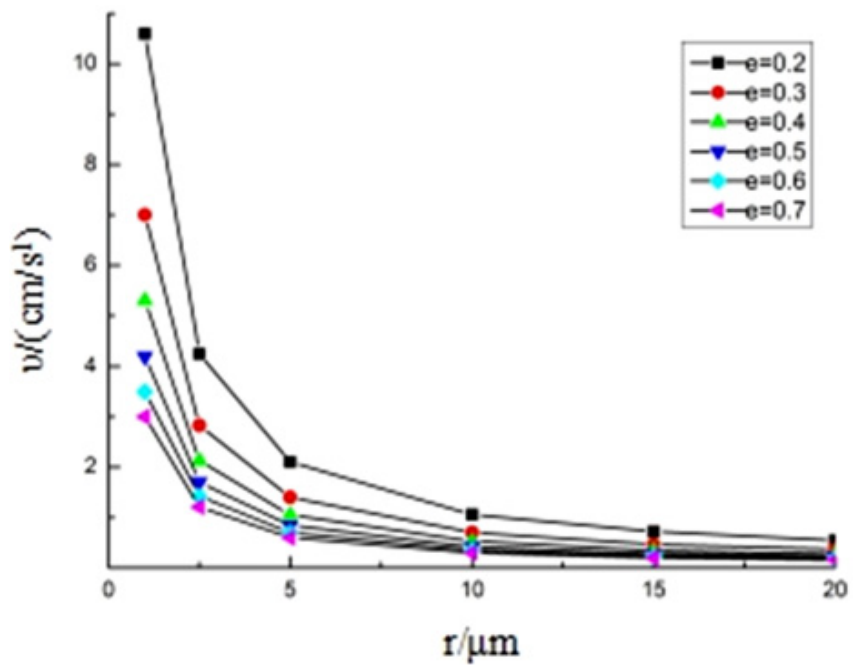

(a) $\mathrm{Al}_{2} \mathrm{O}_{3}$

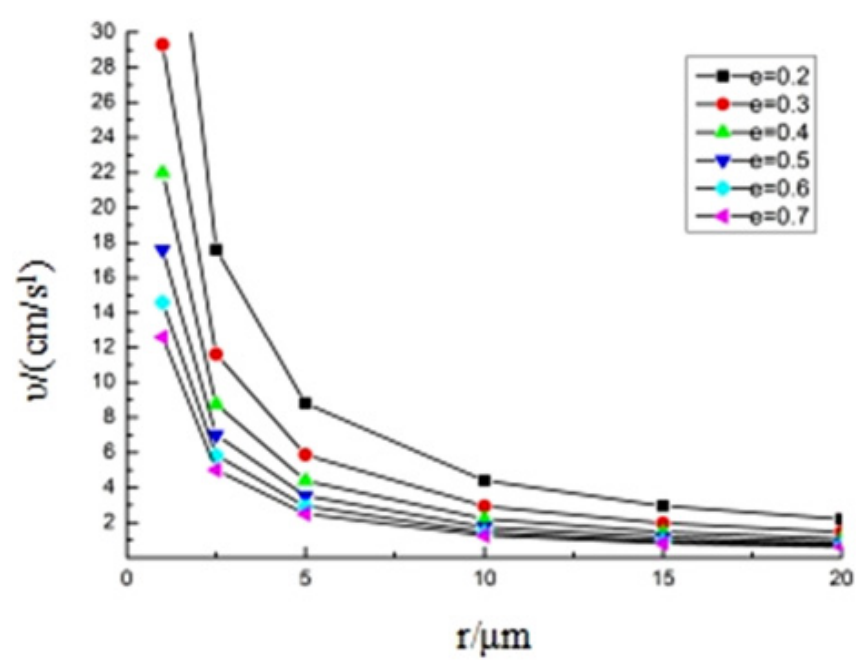

(b) $\mathrm{TiO}_{2}$

Fig. 3. Relation between Radius and Critical Stay Speed of Inclusion under Different Rebound Coefficients

From Fig. 3, it can seen that $r=2.5 \mu \mathrm{m}$ is the critical radius, and the critical stay speeds $v_{\mathrm{Al}_{2} \mathrm{O}_{3}}>1 \mathrm{~cm} \cdot \mathrm{s}^{-1}$ and $v_{\mathrm{TiO}_{2}}>4 \mathrm{~cm} \cdot \mathrm{s}^{-1}$ when $r<2.5 \mu \mathrm{m}$. For these two inclusions, the critical stay speed tends to rise as the radius and rebounding coefficient decrease.

This is because there are energy exchange and energy losses in the process of collision. Kinetic energy decreases with reduced radius when $v_{x 0}$ and e are the same, and the inclusions are more easily to stay in the wall under the van der waals force. While energy loss increases when the e is smaller, and the possibility of rebounding will be reduced.

\subsection{Analysis of critical shear about inclusion}

There are boundary layer and velocity gradient on the wall of outlet. The shear of liquid steel is large. Inclusions stay on the wall of outlet after they accomplish incident and collision. They unable to complete the roll out and be adsorbed because of the shear of liquid steel $(\tau)$. It's called critical shear $\left(\tau_{\omega}\right)$.

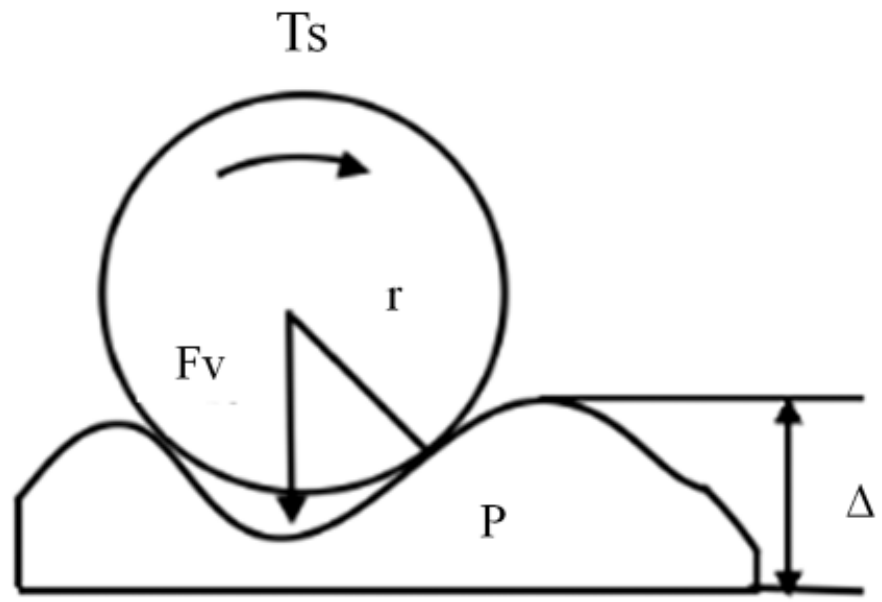

Fig. 4. Schematic of rolling about inclusion
The torque is balanced when the inclusions occur critical scroll and correspond the Eq. (4). $L$ expresses arm, $T_{S}$ expresses torque, $L=r / 2$.

$$
\left.\begin{array}{l}
T_{S}=F_{V} L \\
T_{S}=43.92 \tau_{\omega} r^{3}
\end{array}\right\}
$$

As shown in Fig. 4, inclusions which on the rough wall of outlet occur scroll in fulcrum $P$.

Among them, $\triangle$ expresses the apparent roughness of wall, $\triangle \approx r$ for single dispersion. Therefore:

$$
\tau_{\omega}=F_{v} / 87.84 r^{2}
$$

The critical shear diagram about $\mathrm{Al}_{2} \mathrm{O}_{3}$ and $\mathrm{TiO}_{2}$ is gained according to the Eq. (5). As shown in Fig. 5.

It can be concluded from Fig. 5. The critical shear of $\mathrm{Al}_{2} \mathrm{O}_{3}$ is more than $1 \mathrm{~N} \cdot \mathrm{m}^{-2}$, and the the critical shear of $\mathrm{TiO}_{2}$

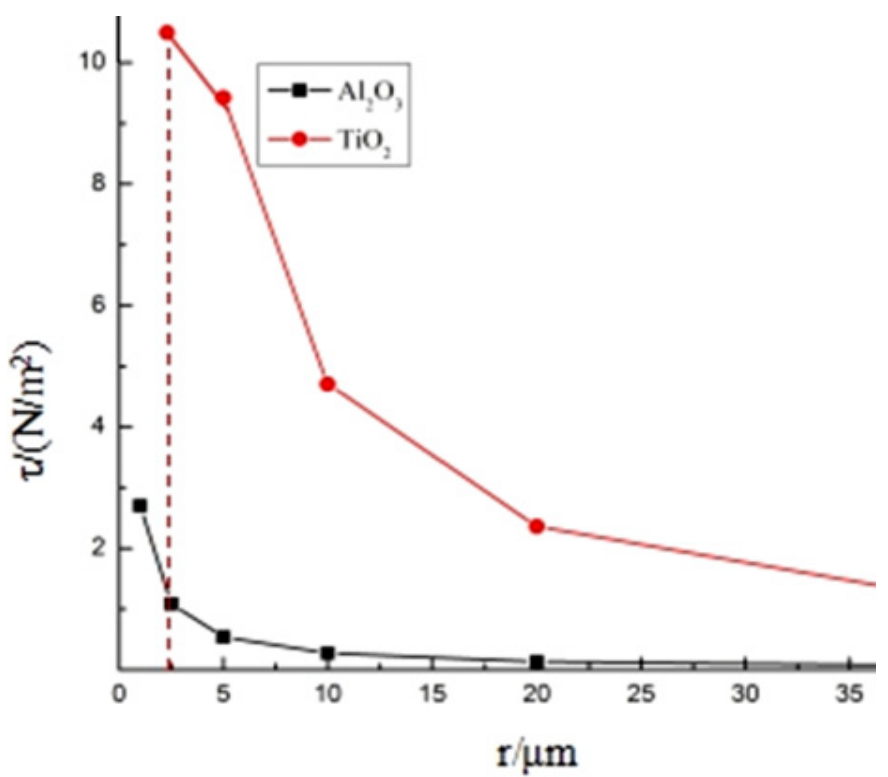

Fig. 5. Relationship between critical shear and inclusion 
is more than $10 \mathrm{~N} \cdot \mathrm{m}^{-2}$ when $\mathrm{r}<2.5 \mu \mathrm{m}$. The larger the size of the inclusions, the smaller the critical shear, and the inclusions are more easily roll out of the wall. $\mathrm{TiO}_{2}$ can resist large shear when they stay in the wall. The shear of liquid steel is less than the $\tau_{\omega}$ below the fold and can be stably adsorbed. Conversely inclusions produce rolling desorption.

Thus the shear of liquid steel that inclusions can afford is related to its diameter. The contact surface between inclusions and liquid steel increases with the diameter. The ability to resist the erosion of liquid steel is more worse.

\subsection{Calculation of inclusion particle rebound}

It is required to consider whether the laminar bottom layer is traversed, when the inclusion rebounds and reenters the steel liquid. Having not traversed the laminar bottom layer, the inclusion will be pushed to the wall surface to be absorbed by it under the efflux effect of interfacial tension, since the steel liquid in the laminar bottom layer flows at a speed nearly equal to zero, or otherwise the inclusion will penetrate the laminar bottom layer. The movement distance of inclusion in steel liquid is shown in Eq. (6) [9]:

$$
Z=2 \rho_{i} r^{2} v_{x 1} / 9 \rho_{f} \eta, \quad H=\delta-Z-2 r
$$

where:

$\delta$ - laminar bottom layer thickness, $20 \mu \mathrm{m}$,

$Z$ - inclusion movement distance, $\mathrm{m}$,

$H$ - the distance from inclusion to laminar bottom layer boundary, $\mathrm{m}$.

The interfacial tension is an impetus and a resistance when the inclusion moves towards the wall surface, and moves from the wall surface to steel liquid respectively. See Fig. 6 , for the inclusion rebound calculation diagram. Distance $H>0$ indicates that the inclusion is still in the laminar bottom layer after rebounding, and it is considered that this part of inclusion is finally absorbed by the wall surface; $H<0$ indicates that the inclusion traverses the laminar bottom layer, and it is preliminarily considered that these inclusions have entered the main flow area of steel liquid.

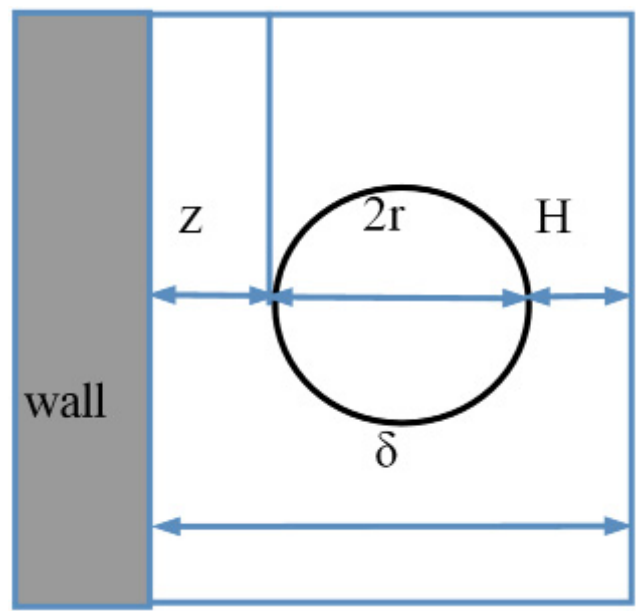

Fig. 6. Inclusion Rebound Calculation
The movement of $\mathrm{r}$ within $1 \sim 20 \mu \mathrm{m}$ and of $v_{x 1}$ within $1 \sim 100 \mathrm{~cm} \cdot \mathrm{s}^{-1}$ are analyzed based on Eq. (6) and with Matlab software. See Fig. 7 for details:

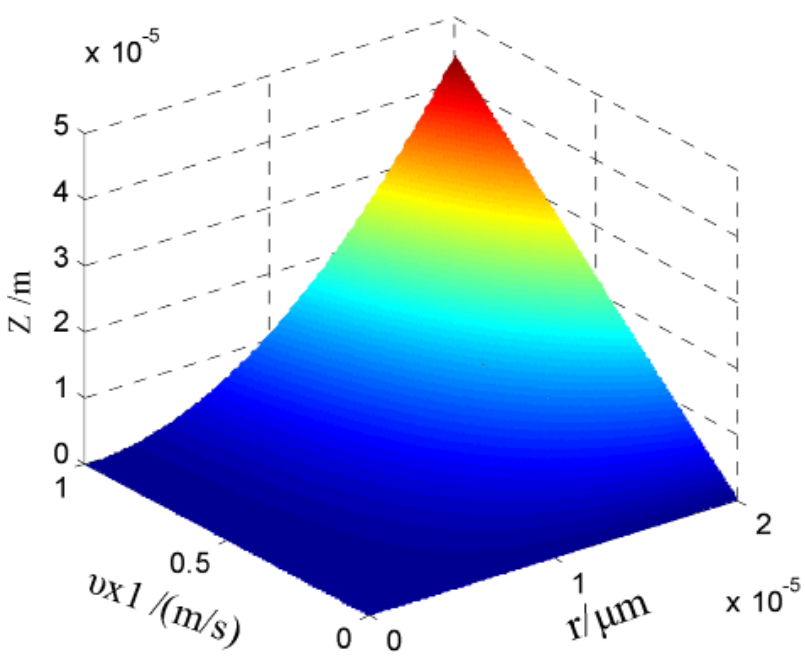

a) Distance $Z$

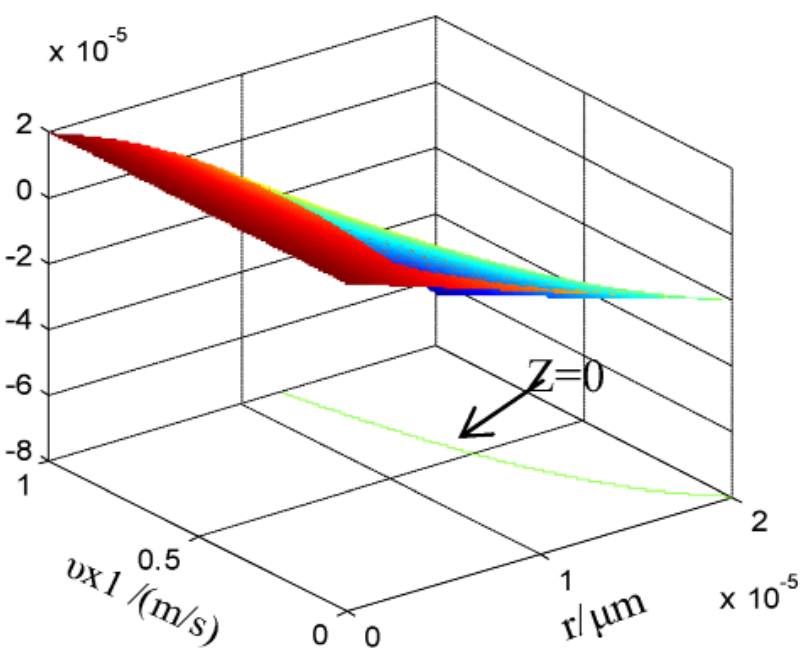

b) Distance $\mathrm{H}$

Fig. 7. Inclusion Rebound Distance

Seen from Fig. 7, $Z$ increases along with the increase of $v_{x 1}$ and $r$. Not all inclusions having rebounded and entered the laminar bottom layer are absorbed by the wall surface, although the flowing speed of laminar bottom layer is low; when $r=7 \mu \mathrm{m}$, the laminar bottom layer cannot be traversed, even if $v_{x 1}=100 \mathrm{~cm} \cdot \mathrm{s}^{-1}$; so it can be considered that the inclusion of $r<7 \mu \mathrm{m}$ is absorbed by the wall surface after entering the laminar bottom layer; the inclusion of $7 \sim 10 \mu \mathrm{m}$ can enter the laminar bottom layer or a boundary layer of high speed, while the inclusion of $r>10 \mu \mathrm{m}$ can easily traverse the laminar bottom layer after rebounding.

In sum, when $\delta=20 \mu \mathrm{m}$, and the inclusion collides with the wall surface and then stays at the wall surface (laminar bottom layer), the inclusion of $r<10 \mu \mathrm{m}$ is absorbed by the wall surface; if the inclusion collides with the wall surface and then 
rebounds, the inclusion of $r<7 \mu \mathrm{m}$ can be absorbed by the wall surface, the inclusion of $7 \sim 10 \mu \mathrm{m}$ can possibly be absorbed, and the possibility that the inclusion of $r>10 \mu \mathrm{m}$ is absorbed by the wall surface is low.

\section{Experimental study on collision and absorption theory}

Take the $20 t$ tundish of a steel works as prototype: for the water simulation, the inclusion content is $0.004 \%$, the inner diameter of intake is $37 \mathrm{~mm}$, the water opening length is $1024 \mathrm{~mm}$, and the tundish level depth is $700 \mathrm{~mm}$. According to the Sahai method [11], the geometric similarity ratio of experimental model and prototype $\lambda=1$, Froud criterion $F_{r}=v 2 / \mathrm{gL}$, the simulated proportion between inclusion in model and $\mathrm{Al}_{2} \mathrm{O}_{3}$ in steel liquid is 2.3 , and thus $\rho=900 \mathrm{~kg} \cdot \mathrm{cm}^{-3}$. The plastic particle of $r=24 \mu \mathrm{m}$ simulates the inclusion of $d=10 \mu \mathrm{m}$, and about $8 \mathrm{~g}$ is added.

See Fig. 8 for the experimental equipment diagram. Make a $4 \times 4 \times 20 \mathrm{~mm}(\mathrm{~L} \times \mathrm{W} \times \mathrm{H})$ rectangular groove at the water open- ing wall surface, and the groove center is $250 \mathrm{~mm}$ away from the stopper rod tip. Add the plastic particle that has been immersed in absolute ethyl alcohol to the position near to the immersed water opening, after the tundish level reaches the specified depth and the flowing speed stabilizes. The groove wall surface is irradiated in parallel with the laser sheet light in the darkroom environment, and the inclusion movement behavior is observed and recorded with high-speed cameras.

The experiment result indicates that the collision and absorption behaviors occur in the process that the inclusion contacts with the wall surface, and it is calculated according to the magnification diameter of Fig. 9 that the movement distance near to the wall surface is about 0 to $8 \mathrm{~mm}$, and the movement speed is $0 \sim 32 \mathrm{~cm} \cdot \mathrm{s}^{-1}$, both of which coincide with the theoretic model.

Select a representative group of pictures which high-speed camera output in $t \mathrm{~ms}$ and observe collision behavior of inclusions.

The trajectory of inclusion in $4277 \mathrm{~ms}$ to $4273 \mathrm{~ms}$ is shown in Fig. 10. The morphology of inclusion which contact wall of groove just a moment ago is relatively vague when $t=4277 \mathrm{~ms}$.

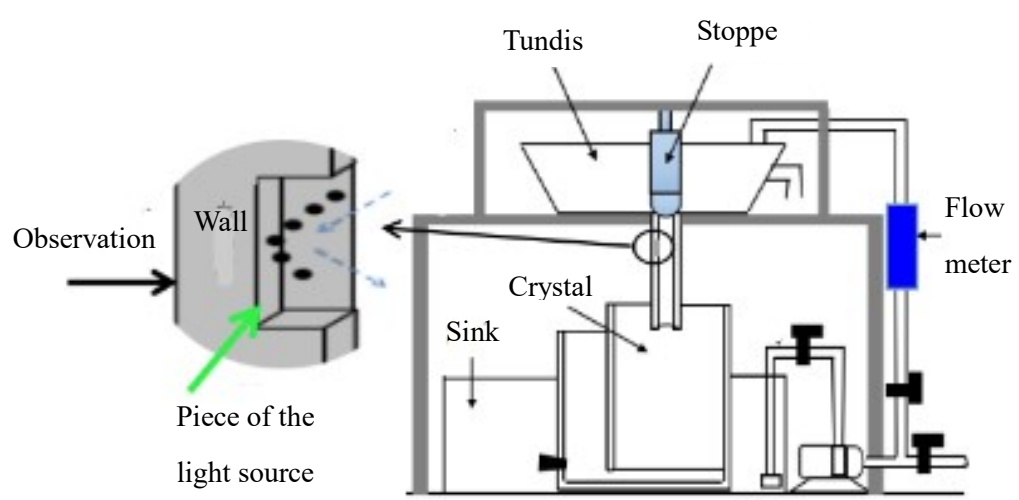

Fig. 8. Experimental Equipment Diagram

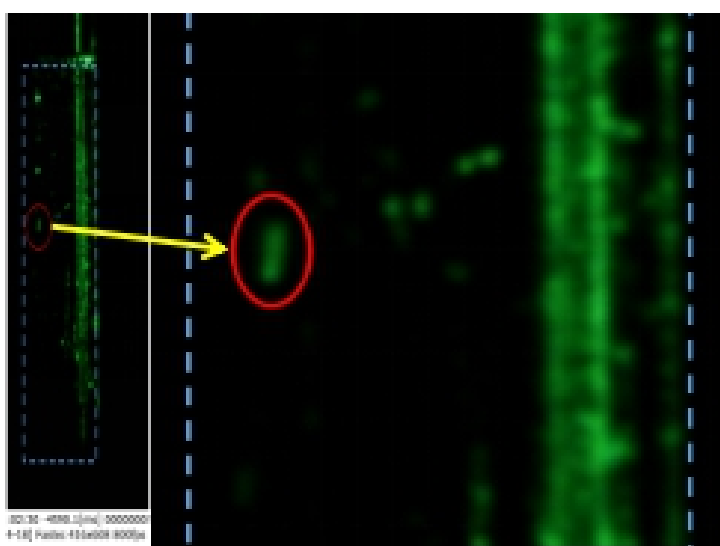

Fig. 9. Inclusion Movement Speed

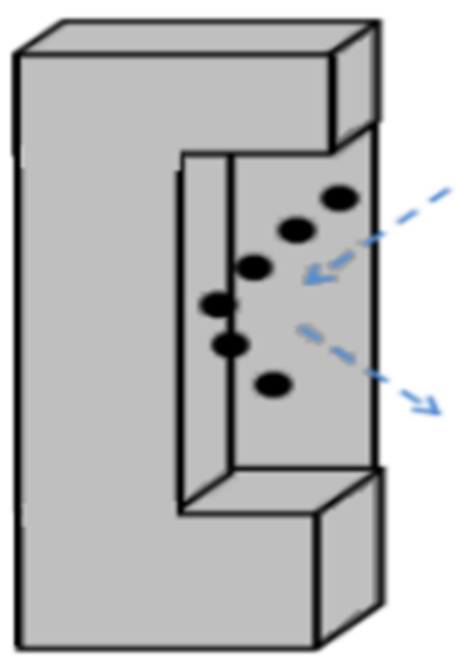

(a) The schematic diagram of rebound

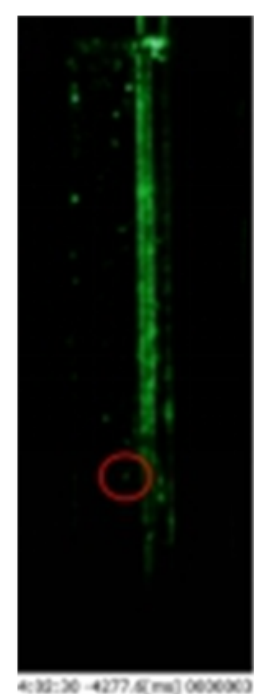

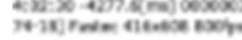
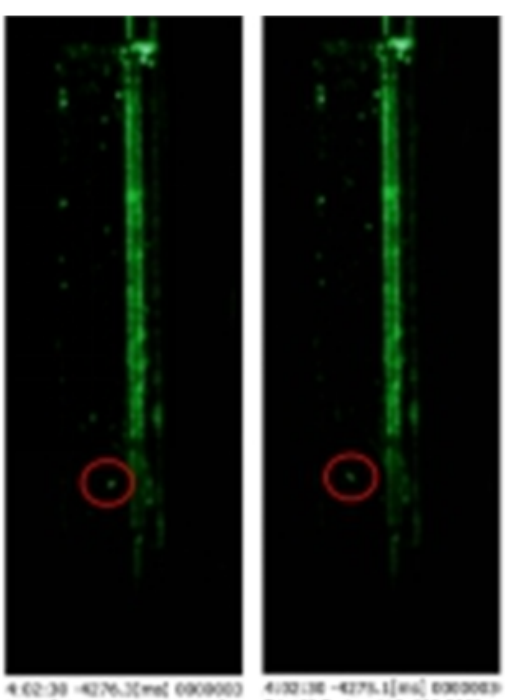

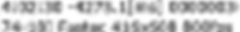

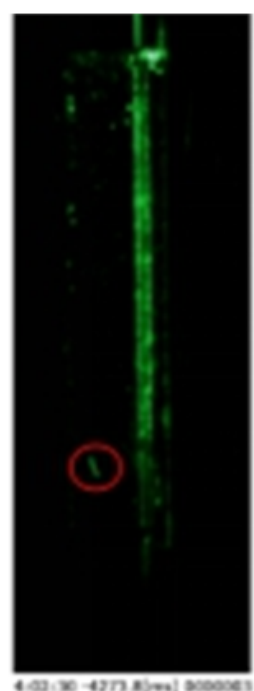

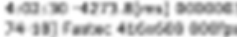

Fig. 10. The process of rebound about inclusions 
Then the morphology of inclusion which in the process of collision compression is relatively clear when $t=4276 \mathrm{~ms}$. However the morphology of inclusion which in the rebound phase is vague again when $t=4275 \mathrm{~ms}$. Finally, inclusions disappear and show some blurred lines at $4273 \mathrm{~ms}$. They pass through the bottom of laminar flow and re-enter the flow field in this circumstance.
The trajectory of inclusion in $4377 \mathrm{~ms}$ to $4337 \mathrm{~ms}$ is shown in Fig. 11. There aren't inclusions on the wall at $4377 \mathrm{~ms}$ while the morphology of inclusion on the wall is relatively clear at $4377 \mathrm{~ms}$ to $4367 \mathrm{~ms}$ and inclusion complete collision. Inclusions stay on the wall at $4362 \mathrm{~ms}$ to $4342 \mathrm{~ms}$ while disappear after $4337 \mathrm{~ms}$

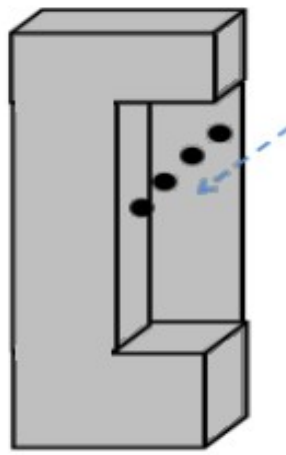

(a) The schematic diagram of retention

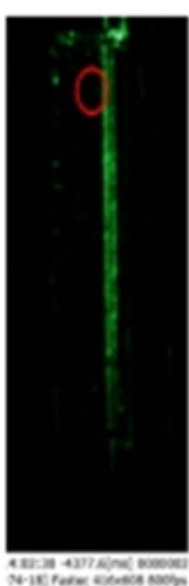

$4377 \mathrm{~ms}$
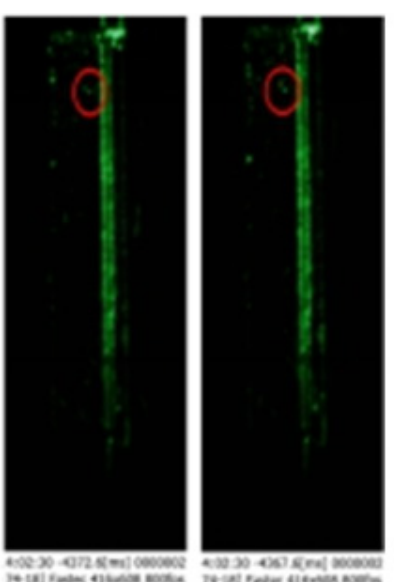

$4377 \sim 4367 \mathrm{~ms}$

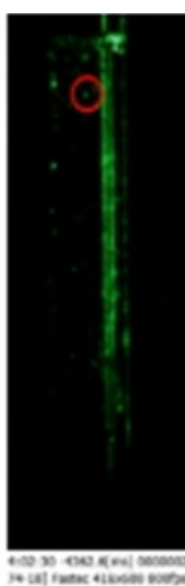

(b) The results of experiment

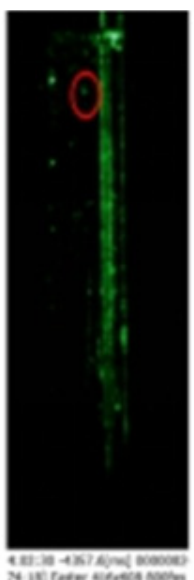

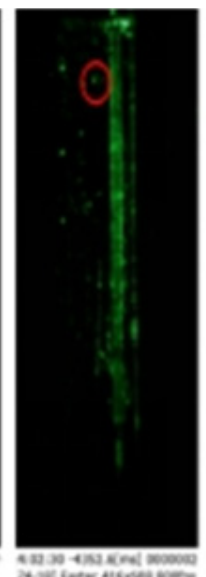
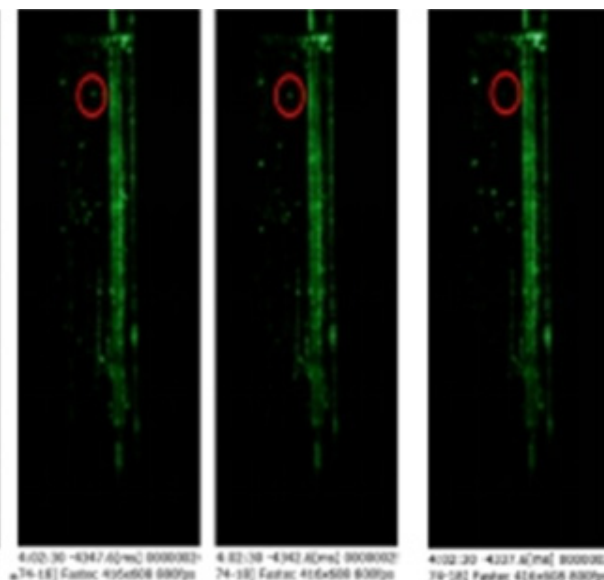

$4362 \sim 4342 \mathrm{~ms}$

$4337 \mathrm{~ms}$

Fig. 11. The process of retention

The motion of inclusions is shown in Fig. 12. Inclusions which stay on the wall will move up slight distance firstly because of the upward and tiny velocity. Then they will slide down some distance.This is because the inclusions that in the laminar layer are effected by the gravity and unstable flow field after speed loss is zero.

The above water simulation experiments show that there is the behavior of adsorption and collision between inclusions and the wall. The experimental results agree with the theoretical analysis.

\section{Conclusion}

(1) The collision and absorption model for high melting point inclusion in steel liquid on immersed water opening wall surface is established, the concept of critical stay speed of inclusion is put forward, and it is calculated that $v_{x 1}=$ $\left[\left(e v_{x 0}\right)^{2}-(2 \mathrm{~W} / \mathrm{m})\right]^{0.5}$, the critical shear $\tau_{\omega}=F_{v} / 87.84 r^{2}$;

(2) The analysis result of collision and absorption model indicates that the critical stay speed and critical shear of alumina respectively surpasses $1 \mathrm{~cm} \cdot \mathrm{s}^{-1}$ and $1 \mathrm{~N} \cdot \mathrm{m}^{-2}$, while titanium dioxide separately exceeds $4 \mathrm{~cm} \cdot \mathrm{s}^{-1}$ and $10 \mathrm{~N} \cdot \mathrm{m}^{-2}$ for the inclusions that radius is less than $2.5 \mu \mathrm{m}$, two types of inclusion decrease with the radius and rebound coefficient, and the critical stay speed tends to increase when $r<2.5$ $\mu \mathrm{m}$ in the laminar bottom layer;

(3) The inclusion of radius is less than $7 \mu \mathrm{m}$ enters the laminar bottom layer and then it is absorbed by the wall surface, the inclusion of $7 \sim 10 \mu \mathrm{m}$ may be absorbed, and the possibility of inclusion of radius is more than $10 \mu \mathrm{m}$ is absorbed by the wall surface is small; 


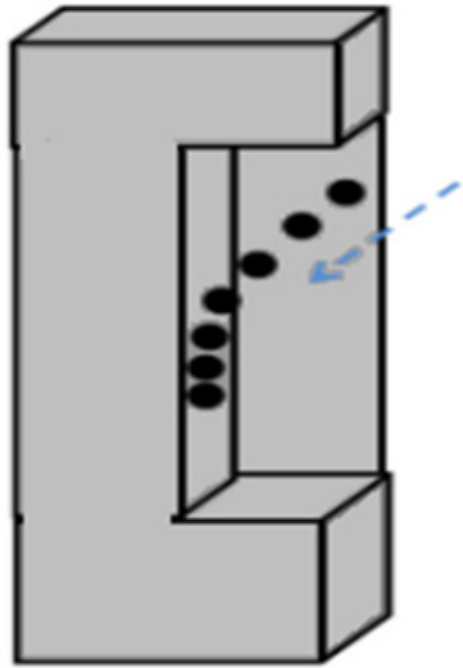

(a) The schematic diagram of movement
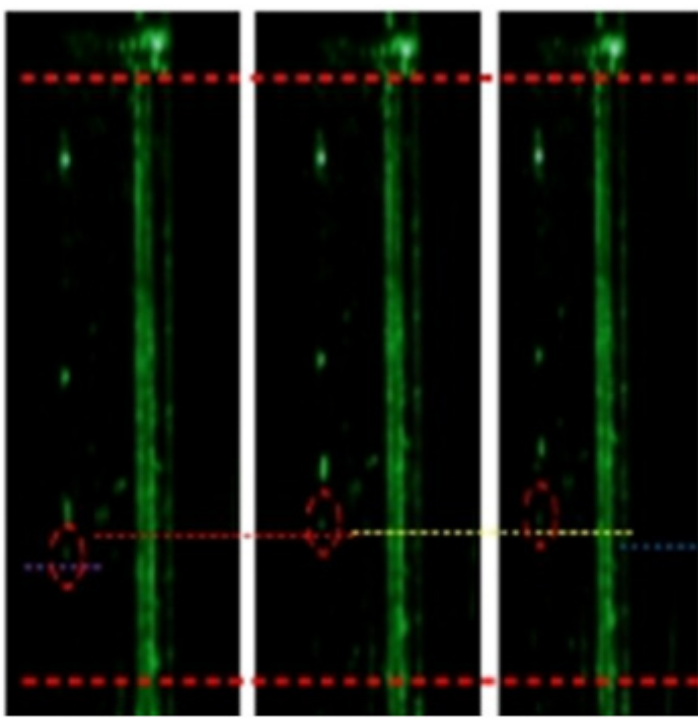

(b) The results of experiment

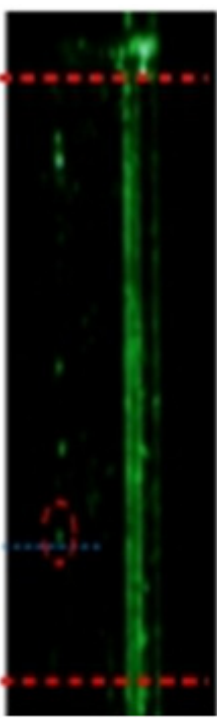

Fig. 12. The process of movement on the wall about inclusion

(4) The water simulation result indicates that the inclusion moving at a speed of $0 \sim 32 \mathrm{~cm} \cdot \mathrm{s}^{-1}$ collides with the wall surface, and coincides with the theoretic model, verifying the inclusion collision and absorption model.

\section{Acknowledgement}

The work was supported by the National Natural Science Foundation of China (No. 51304060) and Science and Technology research of Colleges in Hebei (No. YQ2014011).

\section{REFERENCES}

[1] K. Chattopadhyay, M. Isac, R.I.L. Guthrie, ISIJ Int. 51 (4), $573-$ $580(2011)$
[2] K.A. Kusters, J. Wijers, D. Thoenes, Chem Eng-New York. 5 (20), 107 (1997).

[3] S.N. Singh, Metall. Trans. 5 (10), 2165-2178 (1974).

[4] Y. Qiang, Z. Zong-shu, H. Qin-fu, J. Iron Steel Res. Int. 17 (5), 06-10.(2010).

[5] Y. Fangming, W. Xinhua, Z. Jiongming, et al., Metall. 42 (10), 1109-1114 (2009).

[6] M. Long, X. Zuo, L. Zhang, et al., ISIJ Int. 50 (5), 712-720 (2010).

[7] T. Nakaoka, S. Taniguchi, K. Matsumoto, ISIJ Int. 41 (0), 1103 (2001).

[8] Z. Li-Feng, Taniguch I.S. Hoji, C. Kai-ke, Metall. Trans. B. (31), 253 (2000).

[9] H. Cui, Bao Yanping, W. Meng, et al., Int. J. Min. Met. Mater. 17 (2), 154-158 (2010)

[10] S. Yokoya, S. Takagi, ISIJ Int. 38 (10), 1086-1092 (1998).

[11] Y. Sahai, T. Emi, ISIJ Int. 36 (9), 1166-1173 (1996). 